\title{
Protogyny in a tropical damselfish: females queue for future benefit
}

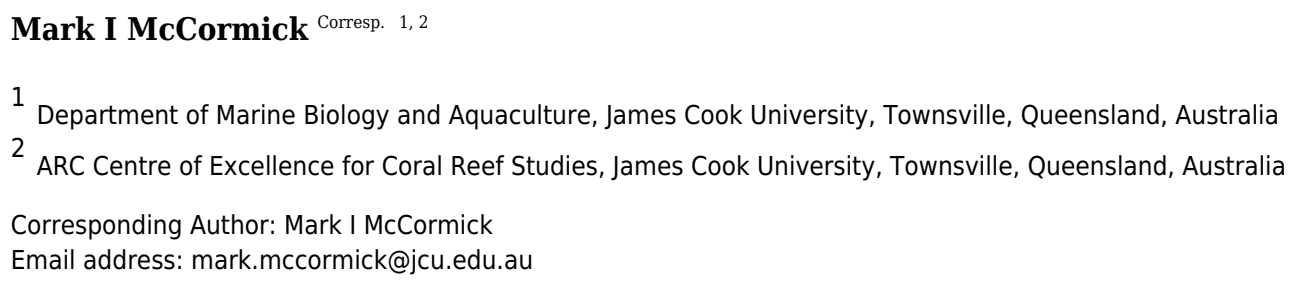

Membership of the group is a balance between the benefits associated with group living and the cost of socially constrained growth and breeding opportunities, but the costs and benefits are seldom examined. The goal of the present study was to explore the trade-offs associated with group living for a sex-changing, potentially protogynous coral reef fish, the Ambon damselfish, Pomacentrus amboinensis. Extensive sampling showed that the species exhibits resource defence polygyny, where dominant males guard a nest site that is visited by females. $P$. amboinensis have a longevity of about 6.5 years on the northern Great Barrier Reef. While the species can change sex consistent with being a protogynous hermaphrodite, it is unclear the extent to which the species uses this capability. Social groups are comprised of one reproductive male, 1 - 7 females and a number of juveniles. Females live in a linear dominance hierarchy, with the male being more aggressive to the beta-female than the alpha-female, who exhibits lower levels of ovarian cortisol. Surveys and a tagging study indicated that groups were stable for at least 3 months. A passive integrated transponder tag study showed that males spawn with females from their own group, but also females from neighbouring groups. In situ behavioural observations found that alpha-females have priority of access to the nest site that the male guarded, and access to higher quality foraging areas. Male removal studies suggest that the alphafemales can change sex to take over from the male when the position becomes available. Examination of otolith microstructure showed that those individuals which change sex to males have different embryonic characteristics at hatching, suggesting that success may involve a component that is parentally endowed. The relative importance of parental effects and social organisation in affecting the importance of female queuing is yet to be studied, but will likely depend on the strength of social control by the dominant members of the group. 
1 Protogyny in a tropical damselfish: females queue for future benefits

2

3 Mark I. McCormick

4 ARC Centre of Excellence for Coral Reef Studies, and Department of Marine Biology and

5 Aquaculture, James Cook University, Townsville, Queensland 4811, Australia

6

7 Corresponding author: Mark I McCormick, as above

8 E-mail: mark.mccormick@jcu.edu.au

9 Phone: +61747814048

10

11

12 


\section{Abstract}

15 Membership of the group is a balance between the benefits associated with group living and the cost of socially constrained growth and breeding opportunities, but the costs and benefits are seldom examined. The goal of the present study was to explore the trade-offs associated with group living for a sex-changing, potentially protogynous coral reef fish, the Ambon damselfish, Pomacentrus amboinensis. Extensive sampling showed that the species exhibits resource defence polygyny, where dominant males guard a nest site that is visited by females. $P$. amboinensis have a longevity of about 6.5 years on the northern Great Barrier Reef. While the species can change sex consistent with being a monandric protogynous hermaphrodite, it is unclear the extent to which the species uses this capability. Social groups are comprised of one reproductive male, $1-7$ females and a number of juveniles. Females live in a linear dominance hierarchy, with the male being more aggressive to the beta-female than the alpha-female, who exhibits lower levels of ovarian cortisol. Surveys and a tagging study indicated that groups were stable for at least 3 months. A passive integrated transponder tag study showed that males spawn with females from their own group, but also females from neighbouring groups. In situ behavioural observations found that alpha-females have priority of access to the nest site that the male guarded, and access to higher quality foraging areas. Male removal studies suggest that the alpha-females can change sex to take over from the male when the position becomes available. Examination of otolith microstructure showed that those individuals which change sex to males have different embryonic characteristics at hatching, suggesting that success may involve a component that is maternally endowed. The relative importance of parental effects and social organisation in affecting the importance of female queuing is yet to be studied, but will likely depend on the strength of social control by the dominant members of the group. 
37 Keywords: Pomacentrus amboinensis; Ambon damselfish; behaviour; carry-over effect; cortisol;

38 dominance hierarchies; mate competition; parental effects; PIT tag; promiscuity; stress 


\section{Introduction}

41 In organisms that live in social groups, members compete for access to limited resources and

42 mating opportunities. Interactions among group members lead to hierarchies of resource allocation

43 with individuals higher up in the social system having greater access to successful mating

44 opportunities. Dominance hierarchies are the building block of stable social systems (Parker, 1974;

45 Maynard-Smith \& Parker, 1976). The social system that develops for a species and the position of

46 individuals within the dominance hierarchy may greatly affect an individual's life history

47 characteristics, such as growth rate and the timing of maturation (Wong et al., 2007), and longevity

48 (Clifton \& Robertson, 1993).

When the reproductive mode of the species involves sex change, the constraints imposed by social interactions prior to and after maturation will affect growth, size-at-age, and likelihood or timing of sex change (Buston, 2003; Munday, Buston \& Warner, 2006; McCormick et al., 2010a). For sex changing species, individuals of the subordinate sex effectively queue for an opportunity to change to the dominant sex and maximise their fitness. To determine how social systems are maintained it is necessary to understand how dominants optimise their negotiating power to maintain a stable social group and how subordinates optimise their own life history strategy and behaviour in response to the behaviour of dominants (Maynard-Smith \& Parker, 1976; Wong et al., 2007; Buston \& Zink, 2009; McCormick et al., 2010a; Clutton-Brock \& Huchard 2013).

Dominants often exert control over a social group by directly or indirectly limiting growth, since in most social hierarchies rank is positively related to size or bulk (Werner \& Gilliam, 1984; Drummond 2006). Subordinates usually have lower access to foraging opportunities, restricted access to high quality food, or spend more time moving to avoid aggressive encounters. Aggressive 
62 interactions often lead to a series of endocrine responses that increase the availability of energy, 63 partly by inhibiting processes not vital for escape or survival (Oliveira, 2004). Subordinates 64 commonly lose interactions and this can lead to elevated glucocorticoid levels (in non-cooperative 65 breeders; Creel, 2001) that in acute cases can lead to reproductive suppression (such as in culture), 66 but in natural systems is more likely to lead to reduced output or offspring that are lower quality 67 (McCormick, 1998; McCormick, 2006; Sheriff \& Love, 2013). Membership of the group is then 68 a balance between the benefits associated with group living (e.g., access to mates, lower per capita mortality; Krause \& Ruxton, 2002) and the cost of socially constrained growth and breeding opportunities. However, the costs and benefits of behaviours within the context of a social system are often assumed rather than demonstrated. It is only when the benefits can be quantified that evolution of social tactics in the context of their reproductive mode can be understood.

Damselfish represent a useful model system that may provide insight into the trade-offs associated with living in a social system constrained by sexual control. Like many coral reef fishes, some damselfishes are protogynous hermaphrodites, meaning they mature as females and transition, if the social system permits, to become a dominant male (Munday, Buston \& Warner, 2006; Savody de Mitcheson \& Liu, 2008). Most damselfish species have life history attributes that are common to non-Pomacentrid fishes: an early larval phase dedicated to development and dispersal, followed by a site attached life phase devoted to growth and reproduction; a settlement transition between life stages that is central to determining their patterns of habitat distribution and density; and a strong social group that influence the trajectory of maturation and lifetime reproductive output.

82 Unlike larger fishes, the small size of damselfishes and their site attached lifestyle permits manipulations of the social system to ascertain the factors that may determine dominance status and reproductive success and the likely costs and benefits of social status. 
85 The goal of the present study was to explore the trade-offs associated with group living within the 86 constraints of the social and reproductive mode they possess. This study focuses on one of the

87 most intensively studied damselfishes, the Ambon damselfish, Pomacentrus amboinensis. This

88 study first describes the social system and sexuality by examining its demography in an area central

89

90

91

92

to the species' distributional range. Behavioural studies of the social hierarchies within groups, hormonal assays and manipulations of group composition enable some of the costs and benefits of living in a protogynous mating system to be examined. In doing so, we gain a better understanding of the benefits of group living that lead to stable hierarchies within groups that exhibit resource defence polygyny.

\section{Materials and methods}

\section{Study species}

Pomacentrus amboinensis, the Ambon damselfish, has a western Indo-Pacific distribution; from Indonesia to Vanuatu, north to the Ryukyu Islands, south to Scott Reef (eastern Indian Ocean) and New Caledonia. Males guard a benthic nest, often a piece of dead coral or a clam shell on a patch of sand or rubble (Fig. 1). Females lay between 1000 to 6000 eggs (Maddams \& McCormick, 2012) on the nest before dawn (McCormick \& Smith, 2004), which is guarded by the male. After a 4 to $5 \mathrm{~d}$ embryogenesis (at $28^{\circ} \mathrm{C}$ ) embryos hatch into $\sim 3 \mathrm{~mm}$ standard length (SL) larvae that have a pelagic larval duration of 15 to $23 \mathrm{~d}$ (Kerrigan, 1996). At the end of the larval phase fish change from being a transparent larvae to a bright yellow juvenile with an ocellus (false eyespot) and have very little morphological alteration associated with metamorphosis (McCormick, Makey \& Dufour, 2002). Around the time of metamorphosis they are attracted to light at night and so are readily caught in light traps (Lönnstedt, McCormick \& Chivers, 2013). The false eyespot on the posterior dorsal fin (i.e., ocellus) is flexible in size and is affected by perceived risk (Lönnstedt, 
108 McCormick \& Chivers, 2013, though see Gagliano, 2008). At settlement, juveniles prefer live 109 coral over rubble habitat when given a choice (McCormick, Moore \& Munday, 2010b). A 110 combination of differential mortality associated with higher survival near territorial males

111 (McCormick \& Meekan, 2007) and interspecific competition (McCormick, 2012; McCormick \&

112 Weaver, 2012) results in juveniles being in highest abundance at the base of shallow reefs in a 113 mixture of sand, rubble, live and dead coral. Jones (1987) examined the size distributions of male, 114 female and immature $P$. amboinensis from One-Tree Island reef and concluded that the species 115 was a protogynous hermaphrodite. Through a histological examination of the gonads Jones (1987) 116 also found that a small number of the largest immature females were transitioning from female to 117 males, which supported his conclusion of hermaphrodism based on the size distribution.

\section{Study site}

119 All research was conducted at Lizard Island, northern Great Barrier Reef, Australia (14²4'S $120145^{\circ} 28^{\prime} \mathrm{E}$ ), with fish collected for demographic analysis during January and February 2001. Lizard 121 Island is a mid-shelf island composed of granite with a well-developed fringing coral reef. $P$. 122 amboinensis were collected from three $\sim 500 \mathrm{~m}$ long locations at Lizard Island: Bommie Bay on 123 the front side of the reef, Watson's Reef at the leeward side of the reef, and within the main lagoon 124 at depths between 3 and $10 \mathrm{~m}$. Behavioural studies and sampling of cortisol levels of individuals 125 within groups were also undertaken from these general locations.

\section{Fish collection}

127 Complete social groups of $P$. amboinensis were randomly collected from each of the 3 locations 128 described above. Social groups were identified by observing groups of interacting $P$. amboinensis 129 for 5 min prior to sampling. Interacting groups of individuals including one or more males, various 
130 numbers of females and juveniles were found in discrete areas separated by space. The male could

131 generally be identified (see Supplementary, Fig. S2) in situ and whether it was guarding a benthic

132 nest site was recorded prior to sampling. The largest female in the area was also recorded.

133 Individuals believed to be new recruits from the current year were not included in the sampling

134 process (fish $<\sim 25 \mathrm{~mm}$ standard length (SL)), with a minimum of 120 fish collected at each

135 location. Individuals were captured using a dilute solution of anaesthetic clove oil and hand nets

136 and returned to the laboratory in $5 \mathrm{~L}$ plastic bags of aerated seawater for processing. Once back at

137 the laboratory, fish were sacrificed using a slurry of crushed ice and seawater. Fish did not struggle

138 and while they would slowly stop ventilating within $30 \mathrm{~s}$, they were left in the ice water at least 5

139 min to ensure death prior to processing. Freshly sacrificed fish were assigned a unique number,

140 blotted dry, weighed $( \pm 0.01 \mathrm{~g})$ and standard length measured with callipers $( \pm 0.01 \mathrm{~mm})$. After

141 measurement, the alimentary system with gonad tissue was removed from each fish and fixed in

142 formaldehyde-acetic acid-calcium carbonate (FAACC; McCormick \& Molony, 1992). Otoliths

143 (sagittae) were removed under a dissecting microscope, cleaned in ethanol and stored dry storage

144 prior to ageing. Because fish were collected in social groups, the gender, size and age composition

145 of the social groups could be determined.

\section{Ethics statement}

147 This research was carried out in accordance with James Cook University ethics guidelines under

148 ethics approval A902 and A851-03 and conducted in accordance with the Queensland Department

149 of Primary Industries collection permit (103256) and a Great Barrier Reef Marine Park Authority

150 research permit (G00/593). All sampling procedures and/or experimental manipulations were

151 reviewed and approved as part of obtaining the above field and ethics permits. 
152 Ageing

153 Age was estimated using the largest of the three otoliths, the sagittae. A thin transverse-section

154 containing the nucleus of one sagittae from each fish was prepared following Wilson and

155 McCormick (1997) and examined under immersion oil with transmitted light microscopy (x 200

156 magnification). Annual growth rings were recorded by counting the number of opaque bands from

157 the nucleus to the outer edge of the otolith. When the last band at the edge of the otolith was

158 approximately half the width of the earlier band, the fish band was recorded as a half-year age. A

159 total of 368 fish were aged for the project.

160 Growth bands in cross-sections of the sagittae were validated as being laid down on an annual

161 basis using tetracycline tagging. Nineteen $P$. amboinensis of a range of sizes (41- $61 \mathrm{~mm} \mathrm{SL)} \mathrm{were}$

162 collected underwater using a hand net and clove-oil, and while still at the capture site placed in a

163 plastic bag, tagged through the bag with a fluorescent elastomer for individual identification (Hoey

$164 \&$ McCormick, 2006), injected into the body cavity with up to $0.2 \mathrm{ml}$ of a solution of tetracycline

165 and saline (50 mg/kg body weight), kept individually in a $5 \mathrm{~L}$ plastic bag for $5 \mathrm{~min}$ to recover, and

166 then released at the collection site. After $18 \mathrm{mo}$, all tagged fish that were still in the area were

167 recollected using a barrier net and hand net, euthanized in a clove-oil overdose and their otoliths

168 were removed. These otoliths were stored in the dark until being sectioned as above and viewed

169 under ultraviolet light. Tetracycline leaves a mark on the otolith cross-sections that fluoresces

170 under ultraviolet light. The number of light and opaque bands after the tetracycline mark were

171 counted and this determined the periodicity of increment formation.

172 Historical determination of gender 
173 Of the 368 fish whose otoliths were sectioned for age determination the clearest were further 174 ground down to make sections $\sim 3-5$ microns thick centred on the nucleus to enable increment 175 counts and measurements within the larval otolith, which was bounded by the settlement mark 176 (Wilson \& McCormick, 1999). Twenty-seven (12 female and 15 male) were clear enough to see

177 into the larval otolith and for these the diameter of the first increment was measured as this 178 represented the size of the sagitta when the fish hatched. A t-test was used to test whether the size 179 of the hatching otolith differed between females and those females that had changed sex to become 180 males. There was no difference in size or age between male and female groups used in the 181 comparison of growth histories $\left(\mathrm{SL}: \mathrm{t}_{25}=-2.217, \mathrm{p}=0.04\right.$, mean male 58.6, female $53.4 \mathrm{~mm}$ SL; 182 age: $\mathrm{t}_{25}=-1.272, \mathrm{p}=0.22$, mean male 4.1, female $3.5 \mathrm{y}$; Bonferroni-adjusted alpha $=0.025$ ).

\section{Cost of spawning with successful males}

184 To determine the extent to which males eat eggs from their nests the gut contents of males from 185 nest sites monitored at 5 locations around Lizard Island (9-10 nest sites per location) were examined after nests had been monitored daily for eggs for 6-weeks during November-December 1994 (McCormick, 1998 for details). At the end of the monitoring study, fish were collected using

188 a barrier net and a dilute clove oil solution, euthanized by clove-oil overdose, and their guts were removed and preserved in FAAC for later examination. The presence of eggs in the guts was quantified on a scale from 0 (empty) to 5 (full to capacity). The relationship of gut fullness with male reproductive success (total number of eggs present in the male nest for the monitored period)

192 was plotted. 
194 Ten groups of $P$. amboinensis containing at least one male, two females and a juvenile were

195 identified at two locations (lagoon and back-reef) and individuals captured with a hand net and

196 dilute clove-oil, measured and then tagged (underwater) for individual recognition with two

197 colours of fluorescent elastomer (see Hoey \& McCormick, 2006 for tagging methodology; see Fig.

1981 for example group). Locations chosen were the edge of a continuous reef and a scaled map of 199 each area was drawn using triangulation. Observations for 15 min were used to identify the male, $200 \alpha$ - and $\beta$-females and juveniles. Locations were visited approximately every two weeks for 3 mo 201 and the position of each individual was plotted on the maps, together with whether they were a 202 member of the original social group. From the maps the mean position for each individual was 203 determined together with the maximum distance from the mean position.

\section{Social interactions and spacing}

205 Fifteen social groups where the male was guarding a nest that contained eggs were examined for 20620 min each and the interactions between fish within the group were tallied to determine position 207 in the dominance hierarchy. Displays (showing side to target and erecting dorsal and anal fins), 208 chases and bites and avoidance events were recorded. The dominant individual was judged to be 209 the individual that had the highest score from the following calculation: displays + chases + bites 210 - avoidances. The position of the group members in relation to the nest and one-another was 211 recorded every $30 \mathrm{~s}$. Feeding rates were also quantified for $\alpha$ - and $\beta$-females from 1 min focal 212 observations. Bites were recorded regardless of whether they were successful or not.

213 Additional observations were made on the $\alpha$-female. The number of interactions and position of 214 the female in relation to the nest site and the male was recorded when the male was present near 215 the nest site, and also while he was away courting other females. 
217 Because female $P$. amboinensis are too small to reliably remove blood from, samples of ovary

218 tissue were collected and frozen for cortisol analysis (as per McCormick, 1998). Fish targeted for

219 cortisol assays were the $\alpha$ - and $\beta$-females in the 15 chosen groups. Levels of cortisol were

220 determined using standard radioimmunoassay (RIA) techniques (protocols see McCormick, 1998)

221 and these were expressed as ng cortisol/g wet ovary weight.

\section{Nest site visitation by females}

223 Females visit the male's nest site to gauge his success in attracting females to lay eggs and guarding

224 the eggs once spawned for the 5 days (at $27^{\circ} \mathrm{C}$ ) of benthic development prior to hatching at 20-30

225 min after sunset (McCormick \& Smith, 2004; Maddams \& McCormick, 2012). One nest site within

226 the shallow lagoon (2 - $5 \mathrm{~m}$ depending on tide) was chosen for an intensive study of female

227 visitation to a male nest site, with tagging methodology detailed in McCormick and Smith (2004).

228 Females within $\mathrm{a} \sim 12 \mathrm{~m}$ radius of the chosen nest site were caught with a fence net, hand net and

229 an anaesthetic clove oil solution, placed into clip-seal bags (as above), tagged in situ with

230 fluorescent elastomer (for individual recognition, as above) and implanted into the body cavity

231 with a passive integrated transponder (PIT) tag (TX1400BE) using a 12G needle. Females were

232 released from the individual plastic bags at the site of capture $10 \mathrm{~min}$ after injection and were seen

233 to resume feeding within 5 min of release. Females ranged in size from 39 to $62 \mathrm{~mm}$ SL (5-11 g).

234 The male nests were chosen because 2-weeks of preliminary observations had found them to be receiving eggs. PIT tag readers (Destron FS2001FT) were placed over the nest site and these

236 recorded the individual code and time stamp whenever a female with a PIT tag entered the nest

237 site (see McCormick \& Smith, 2004 for details, Fig. S3; the monitored nest site was in a similar 
238 area, but not the same nest site as previously reported). The reader was set on a 3 s delay, so that

239 readings from the antenna (determined up to every $60 \mathrm{~ms}$ ) were stored only every $3 \mathrm{~s}$. Because the

240 PIT tag technology uses radio waves, they get dampened after travelling only a short distance when

241 the system is underwater seawater, hence the detector would only be triggered when a PIT tag

242 entered the nest, and every $3 \mathrm{sec}$ that the tagged fish remained in the monitored nest site.

243 Examination of the time that the antenna field was disrupted, together with the tag identity, allowed

244 us to determine approximately how long an individual stayed within the nest site, and how this

245 changed with female size and group membership. The nest site was monitored for $63 \mathrm{~d}$. To evaluate

246 the females' potential contribution to eggs within the nest, the $9 \mathrm{~d}$ period during which eggs were

247 present in the nest was focused on. Males do not tolerate females inside the nest unless they are

248 spawning, and non-spawning females get quickly chased from the nest site. This observation

249 suggests that there should be a relationship between females that spend blocks of time within the

250 nest site and their contribution of eggs to the nest.

251 Male succession

252 My previous experiments on patch reefs involving breeding pairs of $P$. amboinensis have found 253 no evidence of females changing sex when a male is present (McCormick, 1998; McCormick, 254 2006; Maddams \& McCormick 2012). To determine whether a female within an established social 255 group would change sex when the male was removed, ten social groups consisting of 3 females

256

257

258

259

260 and one male were established from fish that were collected from neighbouring continuous reef using a hand-net and anaesthetic clove-oil. They were placed into $5 \mathrm{~L}$ plastic bags of seawater, returned to the dingy, and transported over to the new lagoonal study site in a darkened $60 \mathrm{~L}$ tank filled with seawater to minimise any temperature change. Once at the site they were taken underwater in groups and released onto moderate sized isolated patch reefs on a sandflat located 
261 at least $20 \mathrm{~m}$ apart and $20 \mathrm{~m}$ from the reef edge. Fish were elastomer tagged underwater for

262 individual recognition (as per Social group stability above). Reefs were comprised of live and dead

263 Pocillopora damicornis bushy hard coral $(\sim 1.5 \times 1 \mathrm{~m} \times 0.4 \mathrm{~m})$ together with a plastic half tile (30

$264 \mathrm{~cm}$ long, $18 \mathrm{~cm}$ diameter) that was used as a nesting site by the male. Once fertilized eggs were

265 present on the nesting surface $(1-2$ weeks) behavioural observations allowed the determination

266 of the dominance hierarchy among the females on the patch. Males were then removed from the

267 patch using a fence net and the remaining social group was monitored to determine whether one

268 of the females would take over the nest site and assume the role as a male. Recaptured males were

269 released near their initial site of capture on the main reef ( $>1 \mathrm{~km}$ away). Monitoring was concluded

270 once fertilized eggs were found on the nest site and these were guarded by one of the known

271 females (or another male that migrated onto the reef).

272 Statistical analysis

273 A t-test was used to test for the difference in the diameter of the sagitta at hatching between males

274 and females. An ANCOVA was used to test whether the maximum distance ventured from its

275 mean position on the reef differed among four categories of social status (male, $\alpha$-female, $\beta$-female

276 and juvenile) taking into account the difference in fish size (covariate). Data were normal and

277 homogeneous and a test for homogeneity of slopes was non-significant. A one-factor ANOVA

278 was used to test whether social rank (1-3) of the females affected their position with respect to the

279 edge of the reef. A paired sample t-test was used to test for equality of bite rates (per minute) for

$280 \alpha$ - and $\beta$-females within 15 social groups. A paired sample t-test was also used to test for the

281 equality of mean ovarian cortisol levels between $\alpha$ - and $\beta$-females for the 15 social groups for

282 which data were available. One-factor ANOVAs were used to test for the equality of the distance

283 to the male of the social group and proximity to the nest site between $\alpha$ - and $\beta$-females. For all 
284 tests assumptions were examined with residual analysis. When one-factor ANOVAs (Type III SS

285 when unbalanced) were found to be significant the nature of significance was explored with

286 Tukey's HSD post-hoc tests.

\section{Results}

288 Size, age and gender

289 P. amboinensis start to mature into females at $40 \mathrm{~mm} \mathrm{SL}$, although one female was found to have

290

291

292

293

294

295

296

297

298

299

300

301

302

303

304

oocytes at $34 \mathrm{~mm} \mathrm{SL} \mathrm{(Fig.} \mathrm{2a).} \mathrm{The} \mathrm{modal} \mathrm{size} \mathrm{of} \mathrm{females} \mathrm{was} 53 \mathrm{~mm}$ SL and the largest was 68 $\mathrm{mm}$ SL. Some females were still immature at $48 \mathrm{~mm}$ SL. Testes were found in a $30 \mathrm{~mm}$ SL fish, but generally the smallest individuals with testes were $40 \mathrm{~mm} \mathrm{SL}$, similar to the females. In contrast to females, the modal size of males was $60 \mathrm{~mm} \mathrm{SL}$, with the largest being $78 \mathrm{~mm} \mathrm{SL}$. A small number of non-reproductive 'males' (totalling 12 out of 368 fish) were found evenly spread across size classes between 38 and $68 \mathrm{~mm}$ SL (and across the 3 week collection period). These fish had the same body morphology as mature males (Supplementary, Fig. S2), but had no sign of testes, even after histological inspection. These individuals may have been transitional individuals as these can have very small gonads (Savody de Mitcheson \& Liu, 2008).

Tetracycline marking of otoliths validated that a single opaque and translucent band was laid down during one year. Eighteen months after tetracycline treatment the 8 fish recollected had two opaque bands and one translucent band. The age-frequency histogram shows that the population of $P$. amboinensis at Lizard Island exhibits patterns of change in gender with time (Fig. 2b). As the fish age, they develop from juveniles to females to males, which is marked by the highest frequency of each sex occurring in age classes set 2 years apart. The highest total frequency of juveniles (29), 
305 females (54), and males (30) occupied the 2-year, 4-year, and 6-year age classes respectively. Non306 reproductive males occurred evenly across age classes from 2 to 5.5 years.

307 Juveniles are present in the population until the age of 4, while females and males do not appear 308 in the population until the fish have reached at least the $2 \mathrm{y}$ age class. Females are over twice as 309 abundant in the population as males from the $2 \mathrm{y}$ age class until their peak frequency at $4 \mathrm{y}$ of age, 310 after which they begin to decline in frequency until their maximum $5.5 \mathrm{y}$ of age. Males gradually 311 increase in frequency after the $2 \mathrm{y}$ age class until their peak in the $6 \mathrm{y}$ age class, where neither 312 females nor juveniles are present.

\section{Historical determination of gender}

314 Measurements from cross-sections of the sagittal otolith showed that the width of the hatch mark

315 was slightly larger in those fish that were female, than those that had changed sex to become male $316\left(\mathrm{t}_{25}=-5.432, \mathrm{p}<0.0001 ;\right.$ Mean $\pm \mathrm{sd}$ : Females, $23.53 \pm 0.42 ;$ Males, $20.21 \pm 0.48 ;$ Fig. S5 $)$.

\section{Cost of spawning with successful males}

318 Only 8 out of 47 males that guarded the monitored nests had eggs in their guts at the end of the 6319 week monitoring period (Fig. S4). Egg predation was only found in males that had attracted 320 females that spawned at least 64,000 eggs in their nest. These filial cannibals represented 8 of the 32117 most successful males. Those individuals that fed on eggs had almost totally full guts.

\section{Social group composition and dynamics}

323 On average there was one mature male, 1.5 mature females and one immature individual within 324 the social group (Fig. 3a). The number of females in a group ranged from none to 7, with a mode 325 of two (Fig. 3b). 
326 Social groups were stable over periods of 3 mo during the breeding season at Lizard Island, with

327 no individual from the 14 monitored groups changing membership. During censuses of mapped

328 areas fish moved little over the monitored period, with males moving within groups the same

329 amount as $\alpha$ - and $\beta$-females or juveniles (mean max distance: 1.6, 1.5, 1.5, $1.2 \mathrm{~m}$ respectively;

330 ANCOVA on maximum distance moved, $F_{3,51}=1.853 \mathrm{p}=0.149$ ). Length differences among fish

331 of different social status did not account for a significant amount of variability in distance moved

332 (ANCOVA, SL covariate $\mathrm{F}_{1,51}=0.511, \mathrm{p}=0.478$ ).

333 There was a negative relationship between position within the dominance hierarchy of females

334 within the group and the size of a female relative to the $\alpha$-female (Fig. 4), which accounted for 84

$335 \%$ of the variation in dominance rank. Moreover, females of higher social rank positioned

336 themselves further from the reef edge compared to subordinates (ANOVA, $\mathrm{F}_{2,27}=39.178, \mathrm{p}<$

3370.0001 ; Fig. 5). Alpha-females had higher bite rates than their $\beta$-females within social groups (14.6

338 vs 11.4 bites $\left./ \mathrm{min} ; \mathrm{t}_{14}=5.61, \mathrm{p}<0.0001\right)$.

339 Observations of levels of interactions among females and of females with males suggests that

340 females live in a linear dominance hierarchy (Fig. 6). Dominant ( $\alpha$ ) females are most aggressive

341 to $\beta$-females, show little aggression to $\gamma$-females and avoid males $\left(F_{2,42}=40.54, p<0.0001\right.$; see

342 Fig. 6 for Tukey's tests). Beta-females meanwhile avoid $\alpha$-females and males, but are aggressive

343 to $\gamma$-females $\left(\mathrm{F}_{2,42}=58.301, \mathrm{p}<0.0001\right.$; see Fig. 6 for Tukey's tests $)$.

344 Alpha females had half the cortisol concentrations within their ovarian tissue than $\beta$-females (13.45

345 versus $28.2 \mathrm{ng} / \mathrm{g}$; Paired $\mathrm{t}_{14,0.05}=-3.497, \mathrm{p}=0.004$ ), suggesting the dominant females were less

346 stressed. Alpha females were found closer to the male than either $\beta$-females or juveniles $\left(F_{2,472}=\right.$ 
$34791.054, \mathrm{p}<0.0001$; Fig. 7a). However, $\beta$-females were further away from the nest site than either

$348 \alpha$-females or juveniles $\left(F_{2,472}=168.326, p<0.0001\right.$; Fig. $\left.7 b\right)$.

349 Males displayed to or chased $\beta$-female more than other females associated with the group or a

350 neighbouring group, or the $\alpha$-female $\left(F_{3,36}=30.613, p<0.0001\right.$; Fig. 8). When males were absent

351 from the nest site, such as when they were courting other females, the $\alpha$-female guarded the nest,

352 as indicated by the 8 -fold increase in displays and chases by the $\alpha$-female near the nest site when

353 the male was absent (mean interactions $/ \mathrm{min} \pm$ se; male present, $0.28 \pm 0.04$; male absent, $2.45 \pm$

$\left.354 \quad 0.71 ; \mathrm{F}_{1,14}=9.452, \mathrm{p}=0.008\right)$.

355 Monitoring of the visitations of PIT-tagged females through a nest site found that females were

356 within the nest for a total of 4 h 45 min during the 9-day period (of the 63 days monitored) when

357 eggs were present in the nest. Over this 9-day period, the nest was visited by 24 different females

358 that lived within a $12 \mathrm{~m}$ radius of the nest. No one female monopolized access to the nest, with

359 nine females accounting for $90 \%$ of the time that females spent within the nest site; the other 15

360 females accounted for the remaining $10 \%$. Four of these belonged to the social group of the nest

361 guarding male and were within the top 11 females in their total times spent within the nest (Fig.

362 9). There appeared to be no relationship between the total time within the nest site and female

363 standard length.

364 When males were removed from 10 social groups that had already spawned, the original $\alpha$-female 365 took over the original nest site in 4 instances, while in 3 cases a male from a neighbouring group 366 moved to take over the nest site. In 3 instances there was no change in female status and no males 367 were associated with the group during the monitoring period.

\section{Discussion}


369 The focal species exhibited resource defence polygyny with the male guarding a nest site that is

370 visited by females who make the decision of whether or not to spawn with him. The composition

371 of the group was influenced by processes internal (growth history, aggression, stress) and external

372 (migration) to the group. The presence of a well-defined linear dominance hierarchy amongst

373 group females means the $\alpha$-females have a number of advantages including: access to food; lower

374 stress levels (through lower male aggression); better access to the male and nest site; potentially

375 higher quality larvae (McCormick, 1998; McCormick, 1999; McCormick, 2009); and a higher

376 probability of taking over the nest site with male loss. In a similar way, the male benefits from the

$377 \alpha$-female through her protection of the nest when he is away from the nest site and acting as a

378 reliable source of many, high-quality larvae, due to her large relative size and lower levels of

379 ovarian cortisol.

380 Social groups were found to be spatial stable through time, which is important for the costs and

381 benefits of being in a group to be balanced for an individual over its lifetime. In a tagging study

382 McCormick \& Makey (1997) showed that new recruits did not move more than $1.5 \mathrm{~m}$ in 3 mo.

383 This study indicates that over a 3 mo period that adults and juveniles on the contiguous reef moved

384 little from their initial locations and that they also stayed within the same social group. While many

385 fish move from their initial nursery habitat, usually before maturity (Shulman \& Ogden, 1987;

386 Finn \& Kingsford, 1996), most demersal reef-associated species have small home ranges and show

387 high site fidelity (Marnane, 2000; Verweij \& Nagelkerken, 2007; Nash et al., 2015). Stable social 388 groups are likely to be a dominant feature of many coral reef fish species.

389 The size and age frequency distributions of the sexes, together with the sex change of a number of 390 large females once the dominant males had been removed, suggest that Pomacentrus amboinensis 391 has the capacity to change sex in a way that is characteristic of a protogynous hermaphrodite. 
392 However, in a similar way to the protandrous clownfish Amphiprion clarki, while functional sex

393 change can occur under some conditions, the incidence in nature is unknown (Savody de

394 Mitcheson \& Liu, 2008). For $A$. clarki, dominant females lost from a group were most commonly

395 replaced by females that migrated from outside the social group (Moyer, 1980; Ochi, 1989; Hattori

$396 \&$ Yanagisawa, 1991). In the experimental manipulation of ten social groups, 3 of the social groups

397 had males enter the group, despite being located on patch reefs on sand some $20 \mathrm{~m}$ from the reef

398 edge. The males found without detectable testes in the current study may contribute to the migrants

399 and if so may represent a viable alternative to cueing for an opportunity to change sex from a

400 female once the position of dominant male becomes vacant. In addition it is unclear when in life

401 the majority sex change occurs in the species and the extent to which it is context (e.g., density or

402 habitat) dependent. Prematurational sex change (e.g., Asoh \& Kasuya, 2002 for Dascyllus

403 trimaculatus) may occur, but further studies are required to determine the timing of sex change

404 and the environmental or social conditions that determine the alternative sex-change pathways.

405 The dominance hierarchy of female $P$. amboinensis within the social groups was linear and based

406 on size, with the largest individuals directing most of their aggression toward the next largest

407 individuals. Size is a key factor in determining the outcome of many social interactions including

408 conflict, competitive foraging and mating success (Werner \& Gilliam, 1984; Warner \& Schultz,

409 1992; Persson et al., 1996). These linear hierarchies are common amongst reef fishes (e.g., Castro

410 \& Caballero, 1998), as they are in other organisms (Clutton-Brock \& Huchard, 2013), and enable

411 the dominant individual to obtain access to resources at the expense of the submissive individual,

412 without active aggression. The reduction or absence of aggression means unnecessary energy

413 expenditure and the risk of injury are reduced for both individuals. In one of the few studies to

414 attempt to determine the costs and benefits of being in a hierarchically-structured social group of 
415 tropical fishes, Clifton (1990) found that the removal of large subordinates within groups of

416 parrotfish (Scarus iserti) caused dominant group members to increase their time spent defending

417 territories and decreased their time spent feeding. Such social manipulations would enhance our

418 understanding of the costs and benefits of social group membership for females in the present 419 study species.

420 Dominance status, and probably larger size, had foraging benefits with males on the outer edge of 421 the habitat further from shelter having better access to food. For the mostly planktivorous $P$. 422 amboinensis (McCormick, 2003; McCormick \& Weaver, 2012) individuals that are at the front of 423 the reef are the first to receive food that arrives by currents, and may obtain higher quality food 424 items. Forrester (1990) found that humbug damselfish (Dascyllus aruanus) that were larger 425 occurred on the currentward edge of the reef where they obtained larger food items. This may also 426 come at a cost with respect to survival. Clifton \& Robertson (1993) found that male parrotfish had 427 higher mortality due to their high activity and consequent exposure to predatory trevally. Currently 428 we have no data on the relative survival rates of males compared to females or the sources of this 429 mortality.

430 Benefit of subordinance is that subdominant females get the opportunity to live in a small group 431 associated with a male who will tend their eggs. If the social group is stable, which they appear to 432 be, then a stable hierarchy means that there are fewer challenges and more resources can be put 433 into growth and reproduction. There are other obvious benefits of living in a diffuse group that 434 involve reduced per capita mortality and enhanced feeding associated with the increased vigilance 435 that comes with many eyes (Krause \& Ruxton, 2002). The willingness to accept low social rank 436 may also be a function of limited options outside the group. If resources are stable and able to be 437 monopolised (or very variable and unpredictable), then the high competition and low probability 
438 of small individuals successfully establishing a breeding territory will favour staying within an

439 established group (ecological constraints models, initially developed for cooperative breeding;

440 Emlen, 1982). Subordinates may remain within a group simply because of the benefits of the

441 protogynous social system; the more a dominant profits at the expense of subordinates, the faster

442 it will grow and the faster it will undergo sex-change, promoting the $\beta$-fish into the $\alpha$ position.

443 There is a disjunction between the perceived stable social system and the almost open access of

444 females to the male nest site, and this appears to decouple some of the fitness benefits for females

445 of being a group member from the social interactions that maintain the dominance hierarchy. The

446 high but variable egg mortality found in this species (Emslie \& Jones, 2001) may mean that it is

447 actually advantageous to have females from outside the group contributing to the egg mass on the

448 nest site as it may effectively reduce per egg mortality rates. This is particularly the case as females

449 can only spawn every 2 days (Maddams \& McCormick, 2012), while males can spawn multiple

450 times in a day. When males with egg clutches have been sacrificed at the end of our previous

451 experiments they are often found to contain large numbers of newly spawned $(<24 \mathrm{~h}$ post-

452 fertilisation) eggs in their guts. This in part will be the removal of eggs that are displaying poor

453 development. However, if females choose males to mate with based on the male's ability to garner

454 egg clutches and keep those through to hatching, then all the male needs to do is maintain a large

455 clutch of eggs of a variety of developmental stages to attract females who regularly monitor the

456 progress of nests, as found in other damselfishes (e.g., Gronell, 1989). Because maintaining and

457 guarding eggs is energetically costly (DeMartini, 1987; Marconato, Bisazza \& Fabris, 1993;

458 Lindström, 1998), eating some of one’s own eggs (i.e., filial cannibalism, Smith \& Reay, 1991)

459 may be a cost-effective means of obtaining a high energy meal with exactly the correct nutrient

460 profile for optimal growth. This may be beneficial to both the nest-guarding male and associated 
461 females as he may be able to put more energy into nest site defence (Lindström, 2000). It is

462 currently unknown whether eggs that are eaten are preferentially chosen based on some assessment

463 of quality (size, rate of development etc), or whether clutches received from females outside the

464 male's group are preferentially eaten.

465 The finding that subordinate females have higher ovarian cortisol than $\alpha$-females is in keeping 466 with some of the literature on the endocrine correlates of dominance in fishes (e.g., Fox et al., 467 1997; Oeverli, Harris \& Winberg, 1999). Meta-analyses of the link between stress and dominance 468 conclude that whether or not a subordinate will express elevated cortisol will depend on the social 469 arrangement in the vicinity of the individual (e.g., familiar individuals close by) and also whether 470 the loser is likely to use displacement behaviour to reduce stress (Abbott et al., 2003). The most 471 likely explanation for the present results is that most of the attention of the male and $\alpha$-female is 472 directed towards the $\beta$-female, and it is this aggression that leads to the elevated cortisol levels 473 found in the subordinate female. One of the benefits to the $\alpha$-female is that the male seldom direct 474 aggression toward her, but rather directs it to the $\beta$-female. For the $\alpha$-female this likely results in 475 lower levels of cortisol as a positive correlation has been found between social interactions and 476 the levels of cortisol in the $\alpha$-female of this species (McCormick, 2009).

477 There are many benefits for females to being large relative to other group members. Large females 478 have higher fecundity (Maddams \& McCormick, 2012; Saenz-Agudelo et al., 2015), higher 479 dominance status and lower ovarian cortisol. Experiments on this species have shown that elevated 480 maternal cortisol speed up the embryo developmental (McCormick \& Nechaev, 2002) and results 481 in smaller larvae at hatching (McCormick, 1998; McCormick, 1999; McCormick, 2009), which 482 are more asymmetrical (Gagliano \& McCormick, 2009) and are more likely to have lower survival 
483 during the larval phase (Lemberget \& McCormick, 2009), possibly due to an altered ability to

484 navigate (Gagliano et al., 2008).

485 The characteristics of the embryo appear to influence which individuals are most likely to become 486 male. Those individuals that had transitioned to become males were found to have a smaller otolith 487 diameter at hatching than those that were female. While the sample size is relatively small, these 488 are the first data of their kind for a non-annual species and are supported by more substantial 489 studies on annual protogynous fishes (Walker, Ryen \& McCormick, 2007; Munday et al., 2009; 490 McCormick et al., 2010a). McCormick et al. (2010a) found that females of haremic wrasse, 491 Halichoeres miniatus, who changed sex to male had larger otoliths at hatching, but this was only 492 the case when they occurred in high densities, where the social control within the group was 493 relaxed compared to low-density groups. Little is known of what the size of the otolith at hatching 494 means, but its relationship to larval features, such as size at hatching and yolksac size, appears to 495 be variable and sensitive to maternal-derived cortisol in the embryo and therefore will be strongly 496 affected by maternal effects (Gagliano \& McCormick, 2009; McCormick \& Gagliano, 2009). 497 Given that males in protogynous species are the individuals with the highest lifetime fitness, this 498 study suggests that the fitness of individuals may be, at least in part, pro-rated by characteristics 499 of their mother during gametogenesis.

500 Some groups involved more than one male, but in these the subordinate male did not appear to 501 possess detectable testes. This may occur through weighing the cost of migration and the likelihood 502 of establishing themselves as a dominant in a group against waiting for the death of the dominant 503 male and taking over the group, as has been shown for other animals such as the red fox (Baker et 504 al., 1998). Because these apparently non-reproductive males are difficult to identify while the fish 
505 is alive it was not possible to determine the role these males play in the social organisation of 506 groups.

507 The presence of non-spawning males may be due to the suppression of reproduction by dominant 508 males. A number of studies have found that the presence of dominant conspecifics can suppress 509 reproductive maturation or competence of an individual (mammals: Faulkes, Abbott \& Jarvis, 510 1991; Bennett, Faulkes \& Molteno, 1996; Saltzman, Schultz-Darken \& Abbott, 1996; fishes: Leitz, 511 1987; Cardwell \& Liley, 1991; Pankhurst \& Barnett, 1993). By manipulating social groups of the 512 cichlid Haplochromis burtoni Fox et al. (1997) found that subordinate males had elevated cortisol 513 levels and this lead to subordinates having smaller testes through the suppression of the 514 reproductive hormone axis. Yet this is not always the case, and there are many examples of species 515 in which dominant animals have higher basal glucocorticoid levels than subordinates (for review, 516 see Sapolsky, 1982; Creel, 2001; Milla et al., 2009). In general, however, elevated cortisol levels 517 in adult fishes do lead to reproductive suppression in either females or males (Milla et al., 2009).

518 It is not known in the present study whether non-reproductive male $P$. amboinensis had higher 519 cortisol levels compared to the reproductive dominants, but this is likely to be the case given 520 subordinate females had higher cortisol than dominant females.

521 Sex change occurred at a very variable size and is likely due to the variable composition of social 522 groups, which is a product of the vagaries of recruitment history, migration and disturbances (e.g., 523 predation and habitat change). This suggests that the trajectory of an individual's sexuality is 524 controlled by factors within the group, rather than external to the group (e.g., habitat-specific 525 growth rates). While neither females nor males were reproductively faithful to the social group 526 they frequented, the groups were stable through time, suggesting that the advantages of group 527 living outweighed a looser form of social organisation. Females appeared to queue for the 
528 opportunity to change sex to become the dominant male and were strongly controlled within a

529 linear dominance hierarchy. The relaxation of social stress on the $\alpha$-females may be a factor

530 dissuading them from migrating to nearby habitat, changing sex and establishing their own social

531 group. Dominant females have the benefit of reduced top-down social control, higher egg output

532 (related to their size), an easily accessible nest site (and the additional foraging opportunities this

533 may garner) and a group of familiar subordinate females that they already have a history of

534 dominating when the opportunity arises to change sex and take over the male's nest site. On the

535 other hand, by having the foundation of a stable group, males gain nest site defence (from the $\alpha$ -

536 female) that allows additional courting/mating opportunities, and a constant access to a large

537 number of high quality eggs from the dominant female. While females queue for social dominance,

538 there is the potential that greatness may be preordained because females that had successfully

539 reached dominant-male status were also those that differed in hatching characteristics. While

540 tantalising, the relative importance of this 'silver-spoon effect' compared to social queuing has yet

541 to be determined for this or any other teleost species.

\section{Acknowledgements}

543 We would like to thank Sheng Oon, Jennifer Drost and James Moore for assisting with the

544 processing of the otolith samples used in this study. Shaun Smith ran the cortisol assays and

545 showed dedication to a less than ideal PIT tagging system. B. Kerrigan and numerous others

546 assisted with the field observations and sampling. Yvonne Sadovy de Mitcheson provided very

547 insightful comments on a draft of the manuscript. Data are available at DOI:

548 10.4225/28/55AED3D72AEC8 or https://research.jcu.edu.au/researchdata/default/detail/

$549126597 \mathrm{c} 430 \mathrm{f} 2427 \mathrm{c0509eb53a955eb8e/}$ 
550

551

552

553

554

555

556

557

558

559

560

561

562

563

564

565

566

567

568

569

570

571

572

\section{References}

Abbott DH, Keverne EB, Bercovitch FB, Shively CA, Mendoza SP, Saltzman W, Snowdon CT, Ziegler TE, Banjevic M, Garland T, Sapolsky RM. 2003. Are subordinates always stressed? a comparative analysis of rank differences in cortisol levels among primates. Hormones and Behavior 43:67-82

Asoh, K. and Kasuya, M. 2002. Gonadal development and mode of sexuality in a coral-reef damselfish, Dascyllus trimaculatus. Journal of Zoology 256: 301-309

Baker PJ, Robertson CPJ, Funk SM, Harris S. 1998. Potential fitness benefits of group living in the red fox, Vulpes vulpes. Animal Behaviour 56:1411-1424

Bennett NC, Faulkes CG, Molteno AJ. 1996. Reproductive suppression in subordinate, nonbreeding female Damaraland mole-rats: two components to a lifetime of socially induced infertility. Proceedings of Royal Society London B 263:1599-1603.

Buston P. 2003. Size and growth modification in clownfish. Nature 424:145-146.

Buston PM, Zink AG. 2009. Reproductive skew and the evolution of conflict resolution: a synthesis of transactional and tug-of-war models. Behavioural Ecology, arp050. doi: 10.1093/beheco/arp050.

Cardwell JR, Liley NR. 1991. Androgen control of social status in males of a wild population of stoplight parrotfish, Sparisome viride (Scaridae). Hormones \& Behaviour 25:1-18

Castro JJ, Caballero C. 1998. Dominance structure in small groups of juvenile white-seabream (Diplodus sargus cadenati de la paz, Bauchot and Daget 1974). Aggressive Behaviour 24:197-204

Clifton KE. 1990. The costs and benefits of territory sharing for the Caribbean coral reef fish, Scarus iserti. Behavioral Ecology \& Sociobiology 26:139-147 
573 Clifton KE, Robertson DR. 1993. Risks of alternative mating tactics. Nature 366:520.

574 Clutton-Brock T, Huchard E. 2013. Social competition and selection in males and females.

$575 \quad$ Philosophical Transactions of the Royal Society of London B: Biological Sciences 368:

57620130074.

577 Creel S. 2001. Social dominance and stress hormones. Trends in Ecology and Evolution 16:491$578 \quad 497$

579 DeMartini EE. 1987. Paternal defence, cannibalism and polygamy: factors influencing the 580 reproductive success of painted greenling (Pisces, Hexagrammidae). Animal Behaviour $581 \quad 35: 1145-1158$

582 Drummond H. 2006. Dominance in vertebrate broods and litters. Quarterly Review of Biology $583 \quad 81: 3-32$

584 Emlen ST. 1982. The evolution of helping. I. An ecological constraints model. American $585 \quad$ Naturalist 119:29-39.

586 Emslie MJ, Jones GP. 2001. Patterns of embryo mortality in a demersally spawning coral reef 587 fish and the role of predatory fishes. Environmental Biology of Fishes 60:363-373 588 Faulkes CG, Abbott DH, Jarvis JUM. 1991. Social suppression of reproduction in male naked 589 mole-rats, Heterocephalus glaber. Journal of Reproductive Fertility 91:593-604

590 Finn MD, Kingsford MJ. 1996. Two-phase recruitment of apogonids (Pisces) on the Great $591 \quad$ Barrier Reef. Marine \& Freshwater Research 47:423-432

592 Forrester GE (1990) Factors influencing the juvenile demography of a coral reef fish. Ecology 593 71:1666-1681.

594 Fox HE, White SA, Kao MHF, Fernald RD (1997) Stress and dominance in a social fish. J $595 \quad$ Neurosci 17:6463-6469. 
596 Gagliano M. (2008) On the spot: the absence of predators reveals eyespot plasticity in a marine 597 fish. Behav Ecol 19:733-9.

598 Gagliano M, Depczynski M, Simpson SD, Moore JA (2008) Dispersal without errors:

599 symmetrical ears tune into the right frequency for survival. Proceedings of Royal Society $600 \quad$ London B 275:527-534

601 Gagliano M, McCormick MI. 2009. Hormonally mediated maternal effects shape offspring 602 survival potential in stressful environments. Oecologia, 160:657-665

603

604

605

606

607

608

609

610

611

612

613

614

615

616

617

618

Gronell AM. 1989. Visiting behaviour by females of the sexually dichromatic damselfish, Chrysiptera cyanea (Teleostei: Pomacentridae): a probable method of assessing male quality. Ethology 81:89-122

Hattori A, Yanagisawa Y. 1991. Sex change of the anemonefish Amphiprion clarkii in a habitat of high host density: a removal study. Japanese Journal of Ethology 41:1-8

Hoey AS, McCormick MI. 2006. Effects of subcutaneous fluorescent tags on the growth and survival of a newly settled coral reef fish, Pomacentrus amboinensis (Pomacentridae). Proceedings of 10th International Coral Reefs Symposium 420-425.

Jones GP. 1987. Competitive interactions among adults and juveniles in a coral reef fish. Ecology 68:1534-1547.

Kerrigan BA. 1996. Temporal patterns in the size and condition of settlement in two tropical reef fishes (Pomacentridae: Pomacentrus amboinensis and P. nagasakiensis). Marine Ecology progress Series 135:27-41.

Krause J, Ruxton GD. 2002. Living in groups. New York: Oxford University Press. 210 p.

Leitz T. 1987. Social control of testicular steroidogenic capacities in the Siamese fighting fish Betta splendens Regan. Journal of Experimental Zoology 244:473-478 
619 Lemberget T, McCormick MI. 2009. Replenishment success linked to fluctuating asymmetry in $620 \quad$ larval fish. Oecologia 159:8-93.

621 Lindström K. 1998. Energetic constraints on mating performance in the sand goby. Behavioural 622 Ecology 9:297-300

623 Lindström K. 2000. The evolution of filial cannibalism and female mate choice strategies as 624 resolutions to sexual conflict in fishes. Evolution 54:617-627

625 Lönnstedt OM, McCormick MI, Chivers DP. 2013. Predator-induced changes in the growth of $626 \quad$ eyeballs and false eyespots. Scientific Reports 3:2259

627 Maddams JC, McCormick MI. 2012. Not all offspring are created equal: variation in larval 628 characteristics in a serially spawning damselfish. PLoS ONE 7:e48525

629 Marconato A, Bisazza A, Fabris M. 1993. The cost of parental care and egg cannibalism in the 630 river bullhead, Cottus gobio L. (Pisces, Cottidae). Behaviour Ecology \& Sociobiology

631 32:229-237

632

633

634

635

636

637

638 639

640 641

Marnane M. 2000. Site fidelity and homing behaviour in coral reef cardinalfishes. Journal of Fish Biology 57:1590-1600

Maynard-Smith J, Parker GA. 1976. The logic of asymmetric contests. Animal Behaviour 24:159-175

McCormick MI. 1998. Behaviorally induced maternal stress in a fish influences progeny quality by a hormonal mechanism. Ecology 79:1873-1883

McCormick MI. 1999. Experimental test of the effect of maternal hormones on larval quality of a coral reef fish. Oecologia 118:412-422

McCormick MI. 2003. Consumption of coral propagules after mass spawning enhances larval quality of a damselfish through maternal effects. Oecologia 136:37-45 
642 McCormick MI. 2006. Mothers matter: crowded reefs lead to stressed mothers and smaller 643 offspring in marine fish. Ecology 87:1104-1109

644 McCormick MI. 2009. Indirect effects of heterospecific interactions on progeny quality through $645 \quad$ maternal stress. Oikos 118:744-752

646 McCormick MI. 2012. Lethal effects of habitat degradation on fishes through changing 647 competitive advantage. Proceedings of the Royal Society London B 279:3899-3904

648 McCormick MI, Gagliano M. 2009. Carry-over effects - the importance of a good start. $11^{\text {th }}$ 649 International Coral Reef Symposium. Ft. Lauderdale, Florida, pp. 305-310

650 McCormick MI, Makey LJ. 1997. Post-settlement transition in coral reef fishes: overlooked 651 complexity in niche shifts. Marine Ecology Progress Series 153:247-257

652 McCormick MI, Molony BW. 1992. Effects of feeding history on the growth characteristics of a 653 reef fish at settlement. Marine Biology 114:165-173

654

McCormick MI, Meekan MG. 2007. Social facilitation of selective mortality. Ecology 88:1562655 1570

656

657

658

659

660

661

662

663

McCormick MI, Nechaev IV. 2002. Influence of cortisol on developmental rhythms during embryogenesis in a tropical damselfish. Journal of Experimental Zoology 293:456-466

McCormick MI, Smith SA. 2004. Efficacy of passive integrated transponder tags to determine spawning site visitations by a tropical fish. Coral Reefs 23:570-577

McCormick MI, Weaver C. 2012. It pays to be pushy: intracohort interference competition between two reef fishes. PLoS ONE 7:e42590

McCormick MI, Makey L, Dufour V. 2002. Comparative study of metamorphosis in tropical reef fishes. Marine Biology 141:841-853 
664 McCormick MI, Ryen CA, Munday PL, Walker SPW. 2010a. Differing mechanisms underlie 665 sexual size-dimorphism in two populations of a sex-changing fish. PLoS ONE 5:e10616 666 McCormick MI, Moore JAY, Munday PL. 2010b. Influence of habitat degradation on fish 667 replenishment. Coral Reefs 29:537-546

668

669

670

671

672

673

674

675

676

677

678

679

680

681

682

683

684

Meekan MG, Milicich MJ, Doherty PJ. 1993. Larval production drives temporal patterns of larval supply and recruitment of a coral reef damselfish. Marine Ecology Progress Series 93:217-225

Milla S, Wang N, Mandiki S, Kestemont P. 2009. Corticosteroids: Friends or foes of teleost fish reproduction? Comparative Biochemistry \& Physiology A 153:242-251

Moyer JT. 1980. Influence of temperate waters on the behaviour of the tropical amenonefish Amphprion clarkii at Miyake-Jima, Japan. Bull Mar Sci 30:261-72

Munday PL, Buston PM, Warner RR. 2006. Diversity and flexibility of sex-change strategies in animals. Trends in Ecology \& Evolution 21:89-95

Munday PL, Ryen CA, McCormick MI, Walker SPW. 2009. Growth acceleration, behaviour and otolith check-marks associated with sex change in the wrasse Halichoeres miniatus. Coral Reefs 28:623-634

Nash KL, Welsh JQ, Graham NAJ, Bellwood DR. 2015. Home-range allometry in coral reef fishes: comparison to other vertebrates, methodological issues and management implications. Oecologia 177:73-83

Ochi H. 1989. Mating behavior and sex change of the anemonefish, Amphiprion clarkii, in the temperate waters of southern Japan. Environmental Biology of Fishes 26:257-275 
685 Oeverli O, Harris C, Winberg S (1999) Short-term effects of fights for social dominance and the 686 establishment of dominant-subordinate relationships on brain monoamines and cortisol in

687 rainbow trout. Brain, Behav Evol 54:263-275.

688

689

690

691

692

693

694

695

696

697

698

699

700

701

702

703

704

705

706

Oliveira RF. 2004. Social modulation of androgens in vertebrates: mechanisms and function. Advanced Study of Behaviour 34:165-239

Pankhurst NW, Barnett CW. 1993. Relationship of population density, territorial interaction and plasma levels of gonadal steroids in spawning male demoiselles Chromis dispulis (Pisces: Pomacentridae). General \& Comparative Endocrinology 90:168-176

Parker GA. 1974. Assessment strategy and the evolution of fighting behaviour. Journal of Theoretical Biology 27:223-243

Persson L, Andersson J, Wahlstrom E, Eklov P. 1996. Size-specific interactions in lake systems: predator gape limitation and prey growth rate and mortality. Ecology 77:900-911

Sadovy de Mitcheson Y, Liu M. 2008. Functional hermaphroditism in teleosts. Fish and Fisheries 9:1-43

Saenz-Agudelo P, Jones GP, Thorrold SR, Planes S. 2015. Mothers matter: contribution to local replenishment is linked to female size, mate replacement and fecundity in a fish metapopulation. Marine Biology 162:3-14

Saltzman W, Schultz-Darken NJ, Abbott DH. 1996. Behavioral and endocrine predictors of dominance and tolerance in female common marmosets, Callithrix jacchus. Animal Behaviour 51:657-674

Sapolsky RM. 1982. The endocrine stress-response and social status in the wild baboon. Hormones \& Behaviour 16:279-292 
707 Sheriff M, Love O. 2013. Determining the adaptive potential of maternal stress. Ecology Letters 708 16:271-280

709

710

711

712 benthic mortality? An example in the Caribbean reef fish Haemulon flavolineatum. Marine Ecology progress Series 39:233-242

Smith C, Reay P. 1991. Cannibalism in teleost fish. Reviews in Fish \& Fisheries 1:41-64.

Verweij MC, Nagelkerken I. 2007. Short and long-term movement and site fidelity of juvenile Haemulidae in back-reef habitats of a Caribbean embayment. Hydrobiologia 592:257270

Walker SPW, Ryen CA, McCormick MI. 2007. Rapid larval growth predisposes sex change and sexual size dimorphism in a protogynous hermaphrodite, Parapercis snyderi Jordan \& Starks 1905. Journal of Fish Biology 71:1347-1357

Warner RR, Schultz ET. 1992. Sexual selection and male characteristics in the bluehead wrasse, Thalassoma bifasciatum - mating site acquisition, mating site defense, and female choice. Evolution 46:1421-1442

Werner EE, Gilliam JF (1984) The ontogenetic niche and species interactions in size-structured populations. Annual Review of Ecology \& Systematics 15:393-425

Wilson DT, McCormick MI. 1997. Spatial and temporal validation of settlement-marks in the otoliths of tropical reef fishes. Marine Ecology progress Series 153: 259-271

Wilson DT, McCormick MI. 1999. Microstructure of settlement-marks in the otoliths of tropical reef fishes. Marine Biology 134:29-40 
728 Wong YL, Buston PM, Munday PL, Jones GP. 2007. The threat of punishment enforces peaceful

729 cooperation and stabilizes queues in a coral-reef fish. Proceedings of the Royal Society of

730 London B 274:1093-1099

731

732 


\section{Figure legends}

\section{Figure 1. The Ambon damselfish, Pomacentrus amboinensis, have been used as a model fish}

736 for field and laboratory studies. It is a common component of the damselfish fauna on Indo-

737 Pacific coral reefs and is shown here with smaller $P$. moluccensis, a common competitor for space

738 and resources. $P$. moluccensis are lemon yellow, while the three $P$. amboinensis photographed here

739 have a red tinge on the dorsal surface.

740 Figure 2. Population demographics. Size (a) and age-frequency (b) distributions by gender of

741 Pomacentrus amboinensis at Lizard Island, northern GBR. Plots show males (dark grey), females

742 (white), juveniles (light grey) and non-reproductive males (black). $\mathrm{N}=368$ fish.

743 Figure 3. Social group composition. (a) Composition of a social group, (b) frequency distribution

744 of females within social groups around Lizard island $(\mathrm{n}=95$ social groups). Errors are standard 745 errors.

746 Figure 4. Size affects female status. Relationship between dominance rank of Pomacentrus 747 amboinensis females within a social group and the size of the female relative to the alpha female. Dominance rank was determined from 15 min observation of interactions within social groups (for groups $>2$ females). $\mathrm{N}=119$ fish.

Figure 5. Rank affects space use. Comparison of the distance from the reef edge versus the social

751 rank of the females within a social group of Pomacentrus amboinensis. Errors are standard errors.

752 Letters represent Tukey's HSD groupings of means. $\mathrm{N}=10$ social groups.

753 Figure 6. Levels of aggression displayed by $\alpha$ - and $\beta$-female Pomacentrus amboinensis. Data

754 are from 20 minute behavioural observations on 15 social groups. The aggression index is 
755 calculated using the formula: displays + chases + bites - avoidances. Errors are standard errors.

756 Letters represent Tukey’s HSD groupings of means.

757 Figure 7. Rank affects access to resources for females. Proximity of female Pomacentrus 758 amboinensis to the male (a) or nest site (b). Errors are standard errors. Letters represent Tukey's 759 HSD groupings of means. $\mathrm{N}=8$ social groups.

760 Figure 8. Males are more aggressive to subordinate females. Frequency of interactions by 761 males Pomacentrus amboinensis with females or juveniles. Errors are standard errors. Letters 762 represent Tukey's HSD groupings of means. $\mathrm{N}=10$.

763 Figure 9. Males are promiscuous. Time spent inside the male Pomacentrus amboinensis nest by 764 females of various sizes. The dominant female $(\alpha)$ and other females primarily associated with the 765 social group are indicated (squares). Note that time is on a $\log 10$ scale. Data are from PIT tagged 766 females entering a radio monitored nest site over a period of 9 days when eggs were present in the 767 nest. 
772 Figure 1.

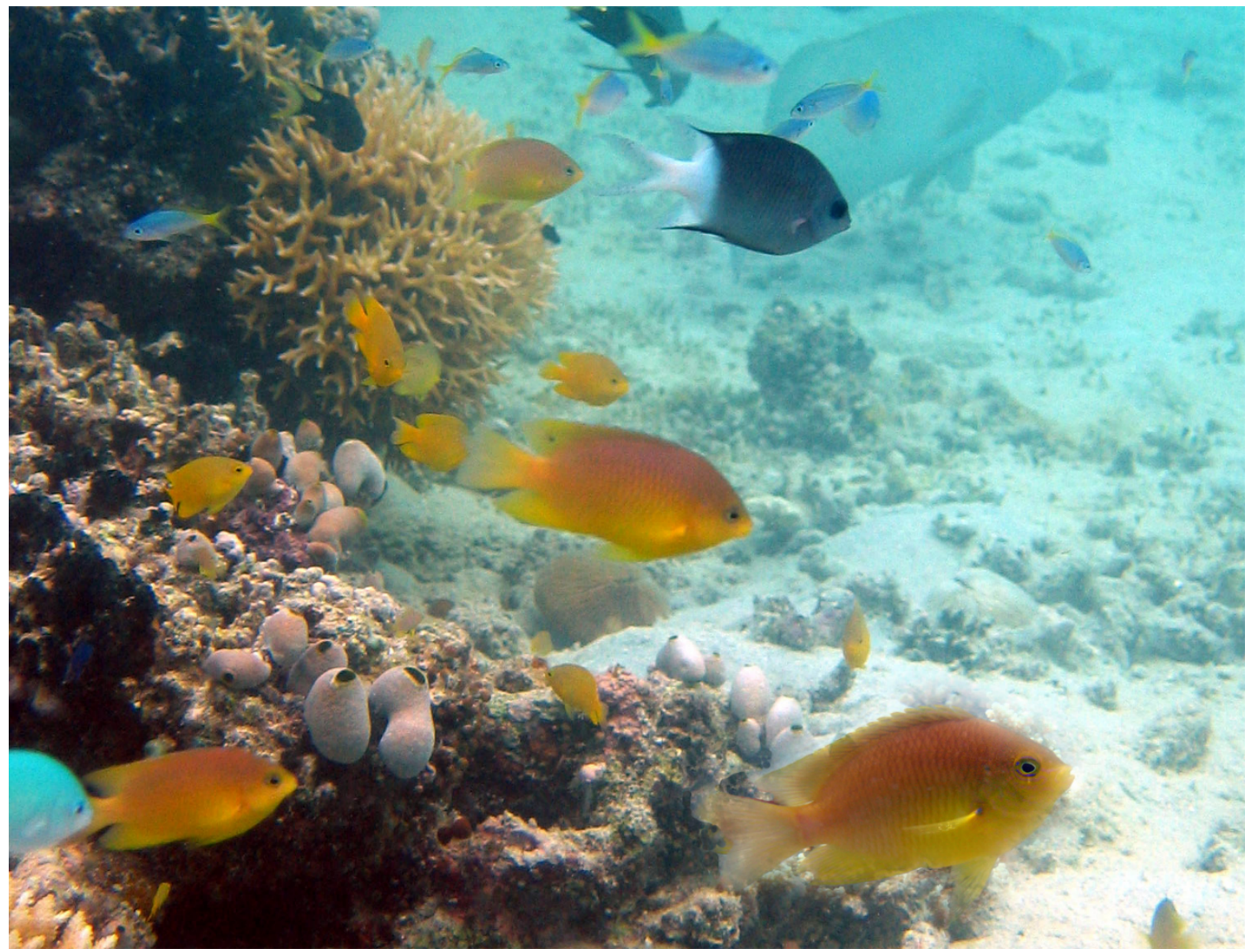

Figure 1. The Ambon damselfish, Pomacentrus amboinensis, have been used as a model fish amboinensis photographed here have a red tinge on the dorsal surface. 
Figure 2

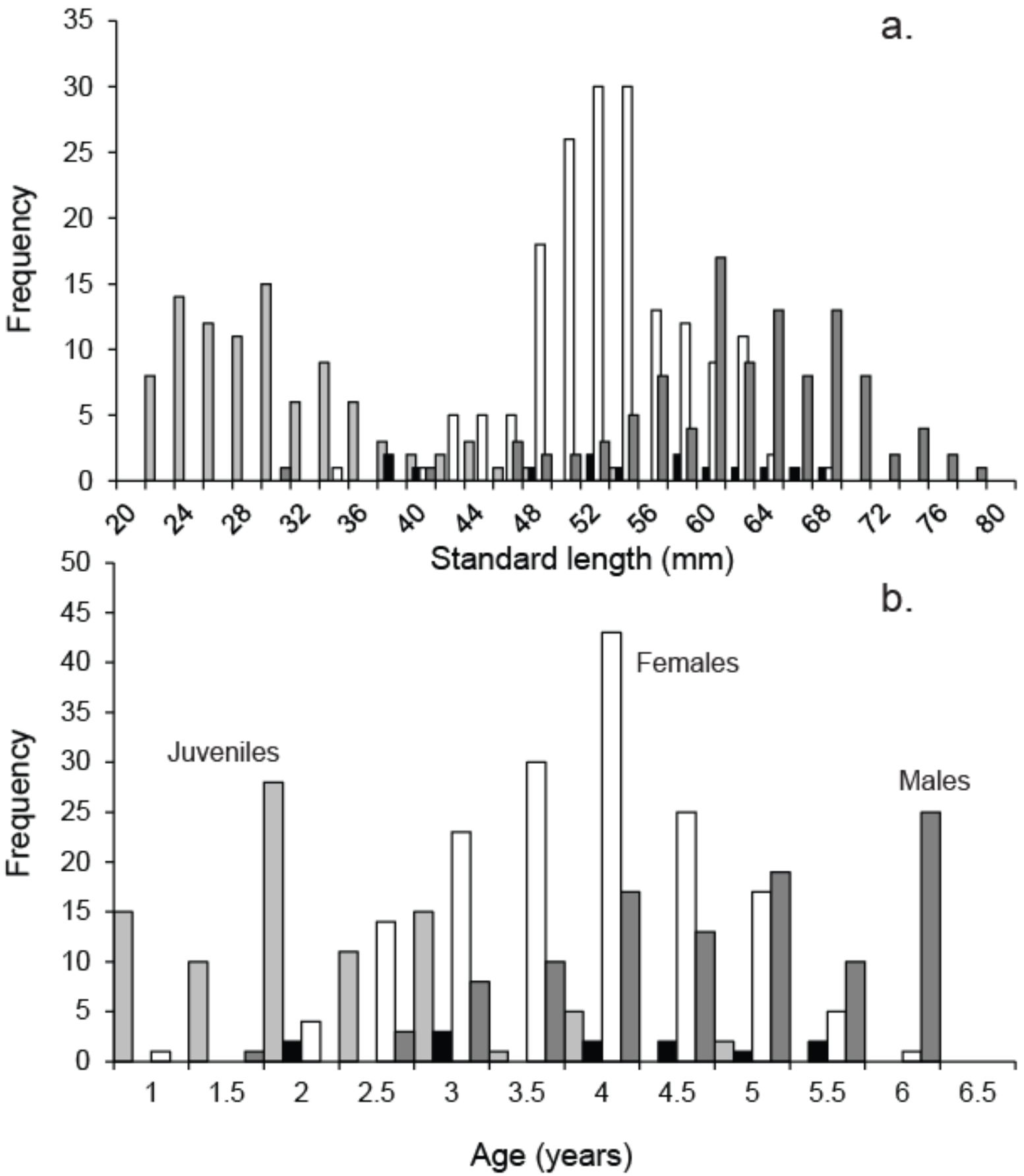


784 Figure 2. Population demographics. Size (a) and age-frequency (b) distributions by gender of 785 Pomacentrus amboinensis at Lizard Island, northern GBR. Plots show males (dark grey), females 786 (white), juveniles (light grey) and non-reproductive males (black). $\mathrm{N}=368$ fish. 
Figure 3
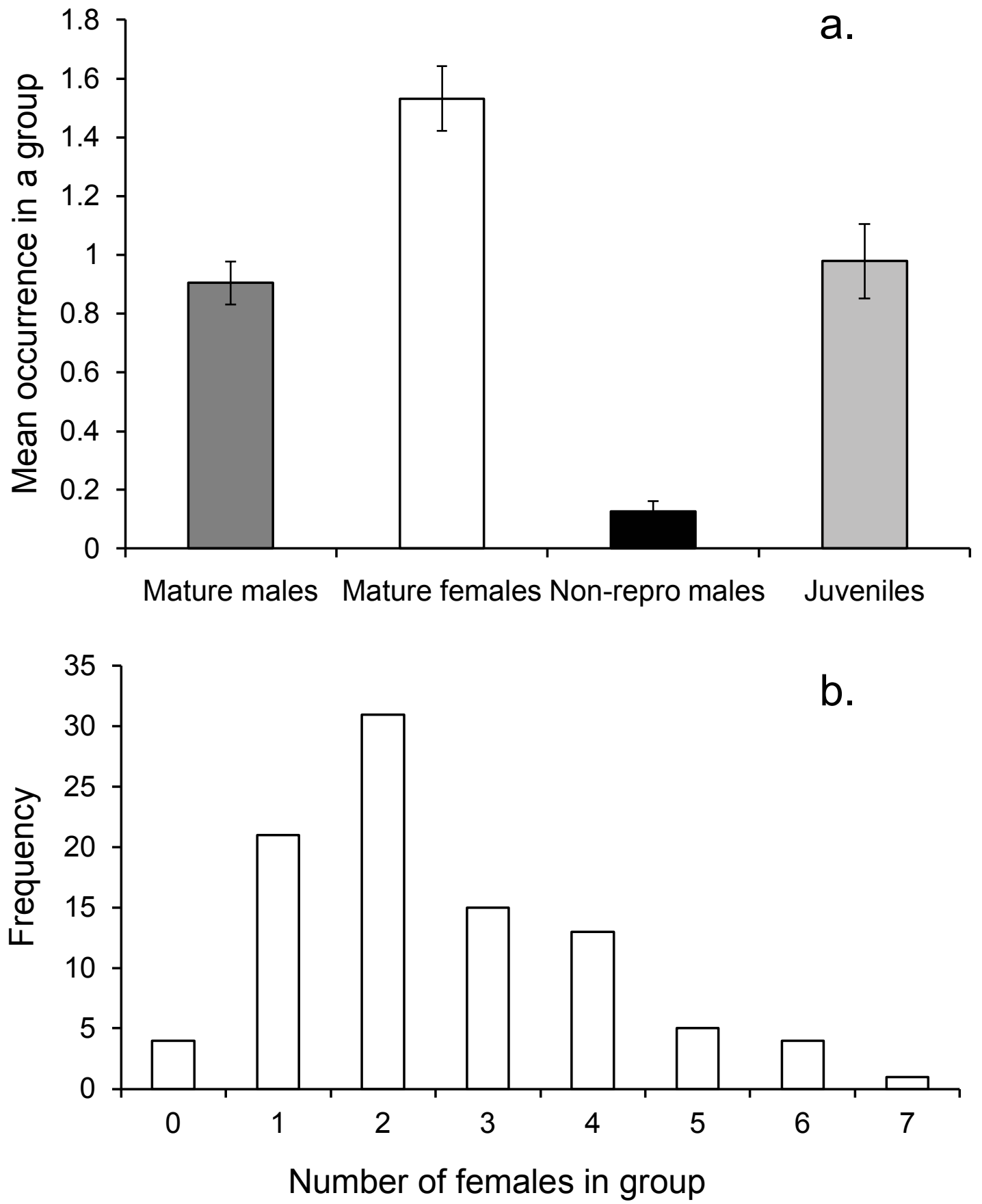

789

790 Figure 3. Social group composition. (a) Composition of a social group, (b) frequency distribution

791 of females within social groups around Lizard island ( $\mathrm{n}=95$ social groups). Errors are standard 792 errors. 
795 Figure 4

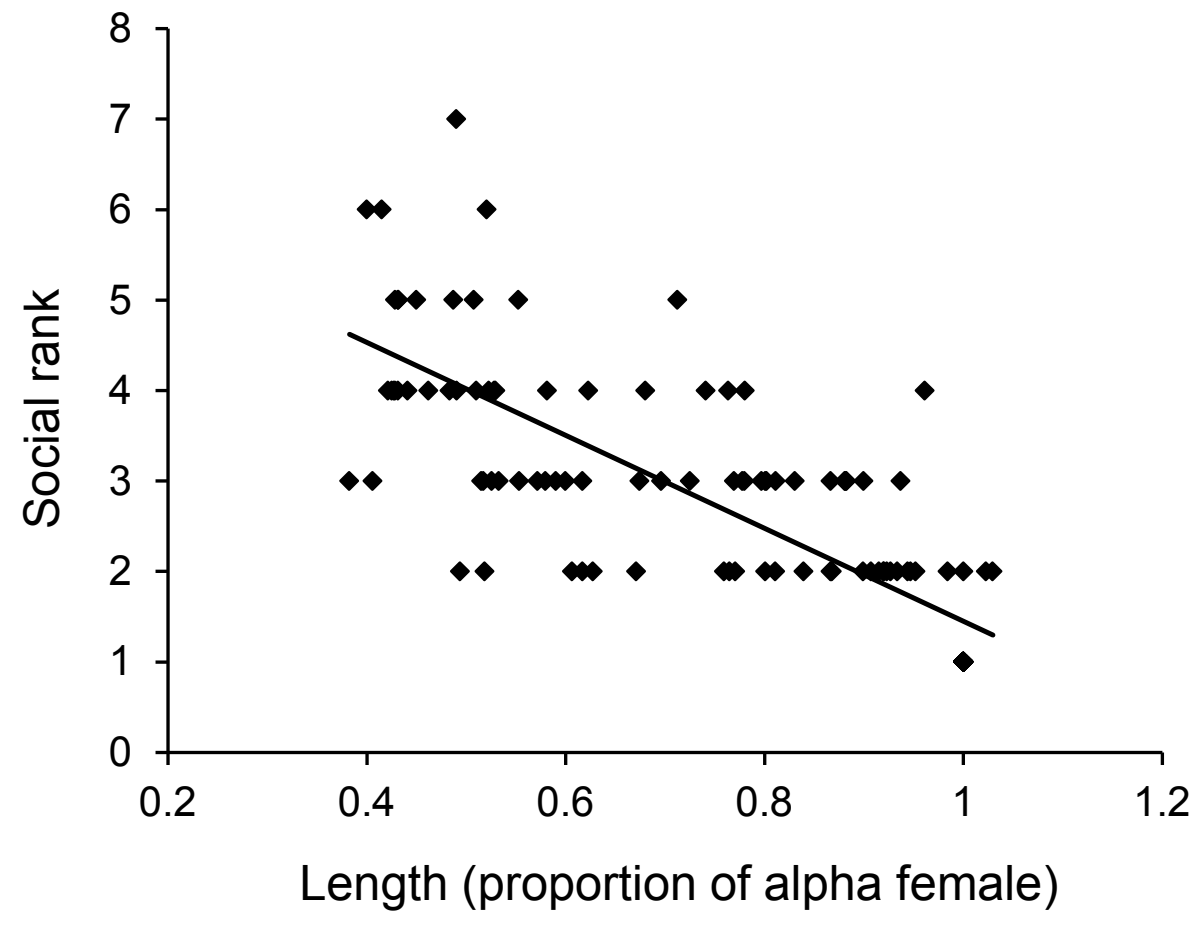

796

797 Figure 4. Size affects female status. Relationship between dominance rank of Pomacentrus 798 amboinensis females within a social group and the size of the female relative to the alpha female.

799 Dominance rank was determined from 15 min observation of interactions within social groups (for 800 groups $>2$ females). $\mathrm{N}=119$ fish. 
803 Figure 5.

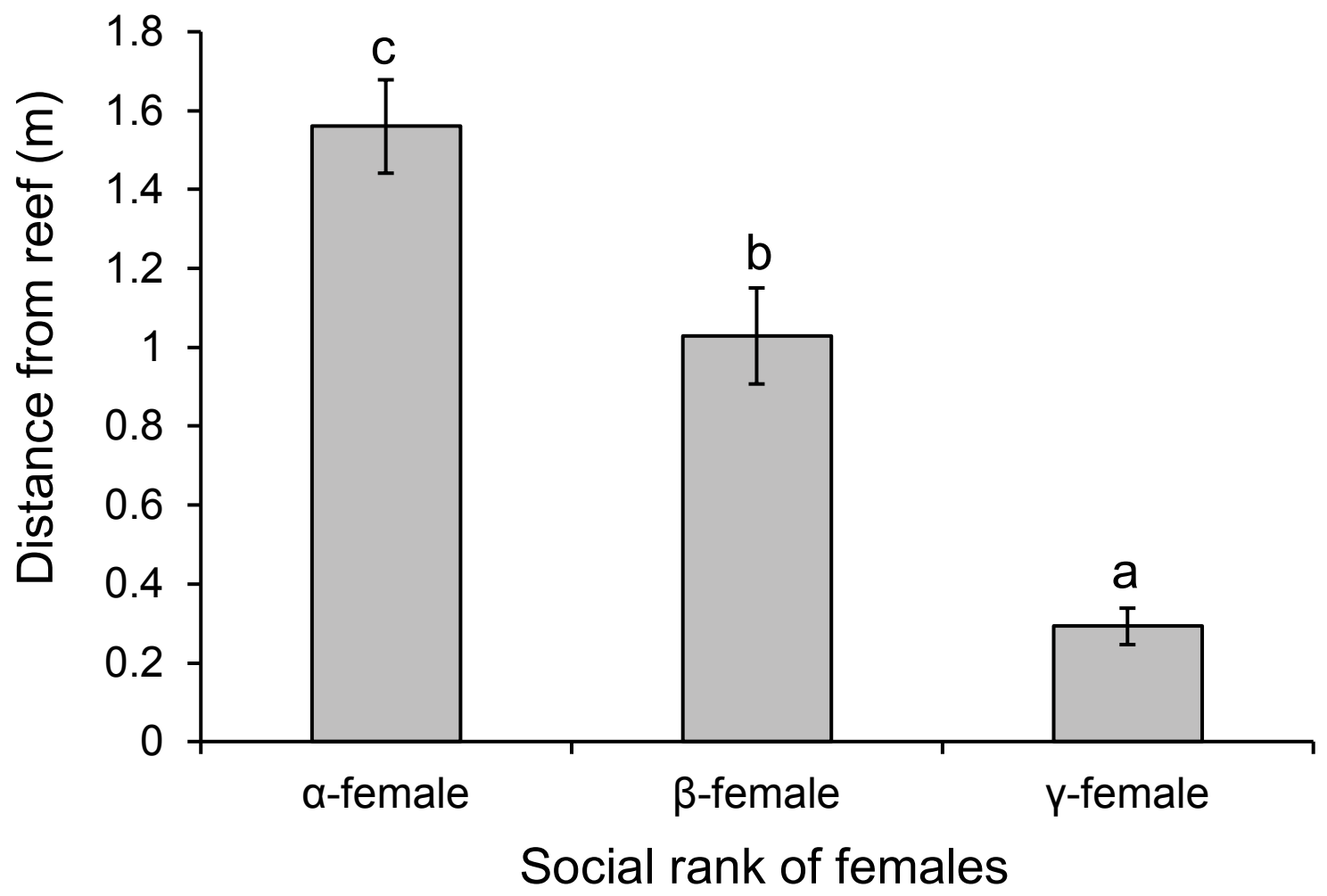

804

805 Figure 5. Rank affects space use. Comparison of the distance from the reef edge versus the social

806 rank of the females within a social group of Pomacentrus amboinensis. Errors are standard errors.

807 Letters represent Tukey's HSD groupings of means. $\mathrm{N}=10$ social groups. 
810 Figure 6.

811

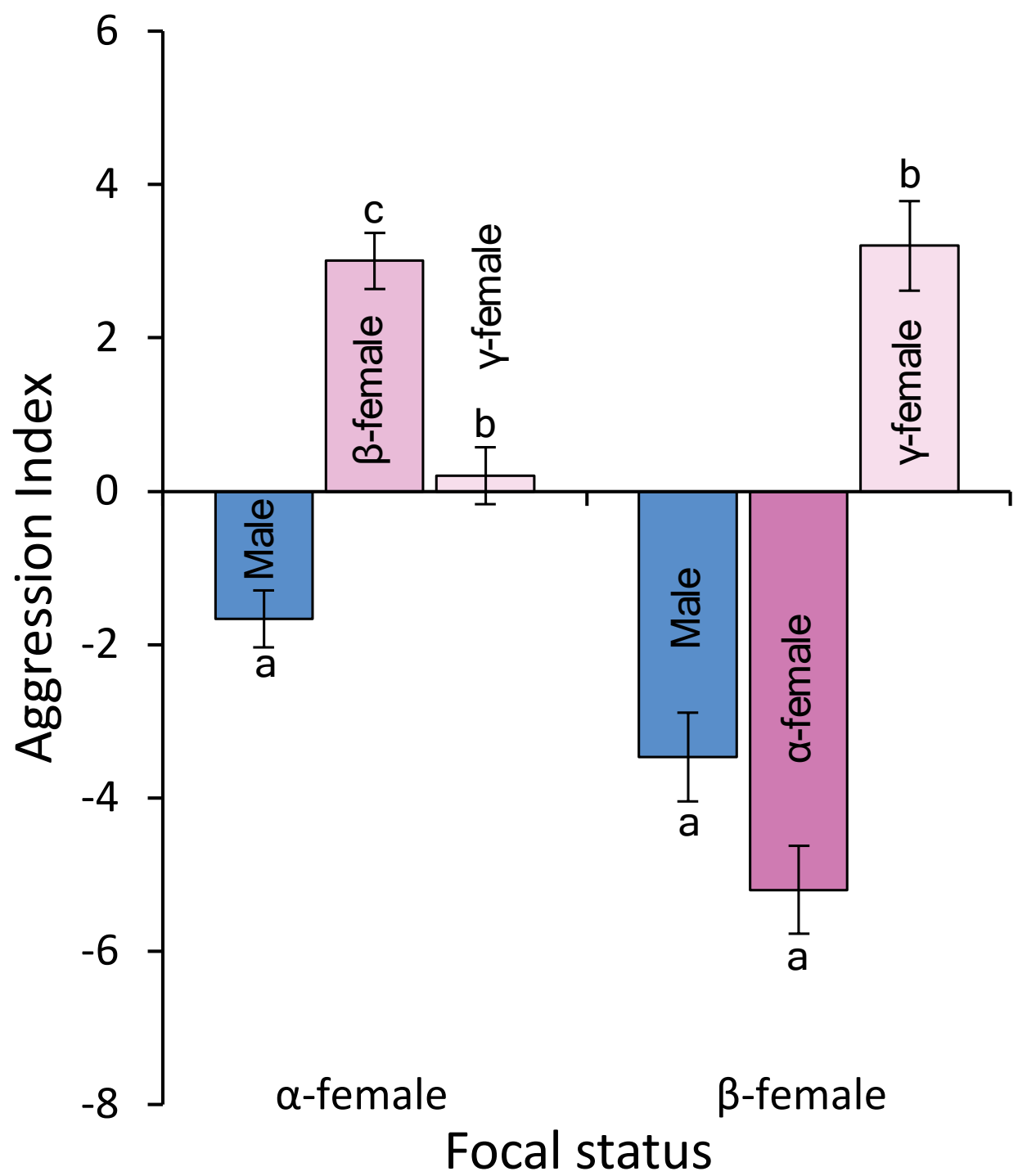

812

813 Figure 6. Levels of aggression displayed by $\boldsymbol{\alpha}$ - and $\boldsymbol{\beta}$-female Pomacentrus amboinensis. Date

814 are from 20 minute behavioural observations on 15 social groups. The aggression index is

815 calculated using the formula: displays + chases + bites - avoidances. Errors are standard errors.

816 Letters represent Tukey’s HSD groupings of means. 
818 Figure 7
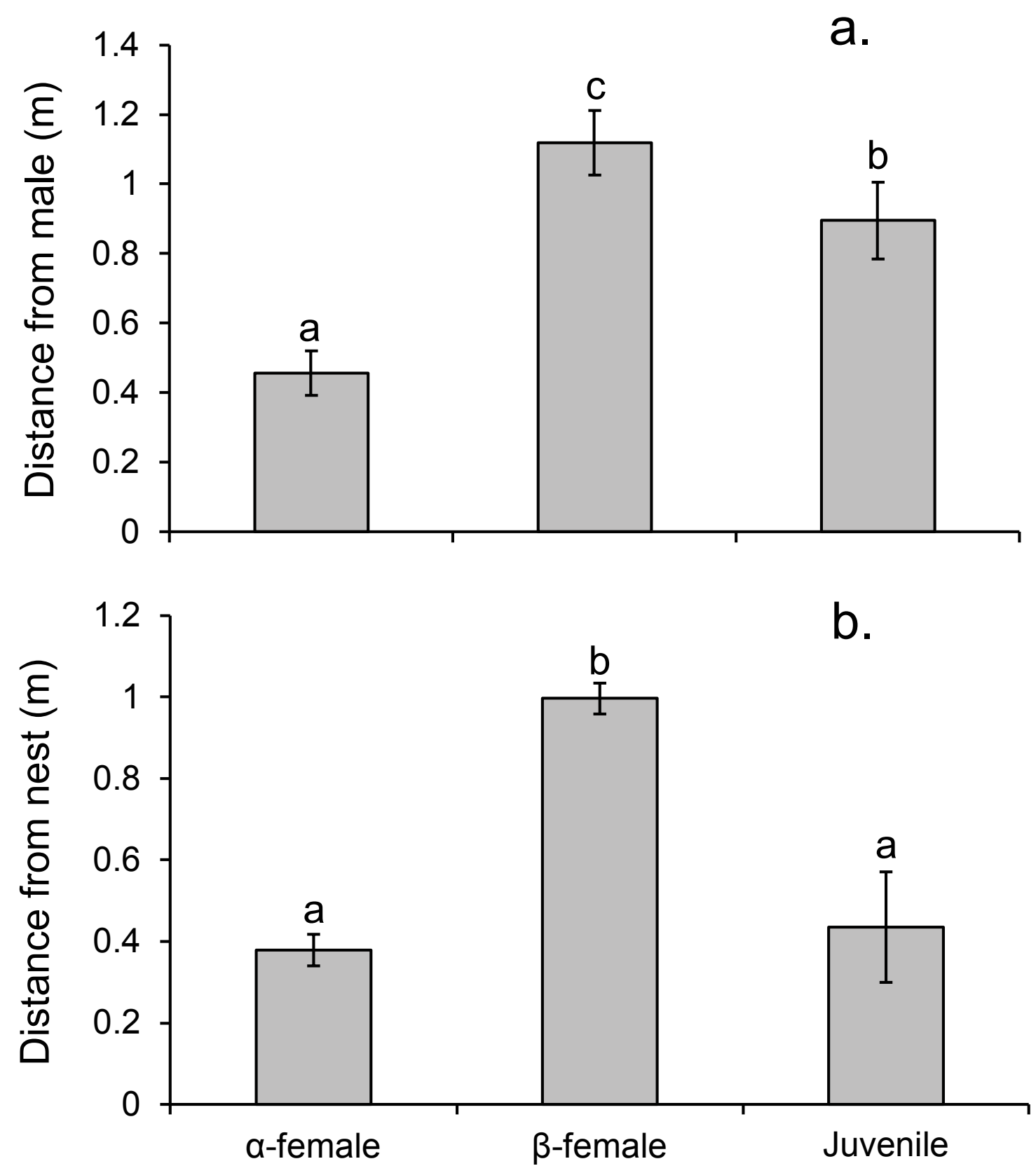

Female status 
820 Figure 7. Rank affects access to resources for females. Proximity of female Pomacentrus

821 amboinensis to the male (a) or nest site (b). Errors are standard errors. Letters represent Tukey's

822 HSD groupings of means. $\mathrm{N}=8$ social groups. 
824 Figure 8

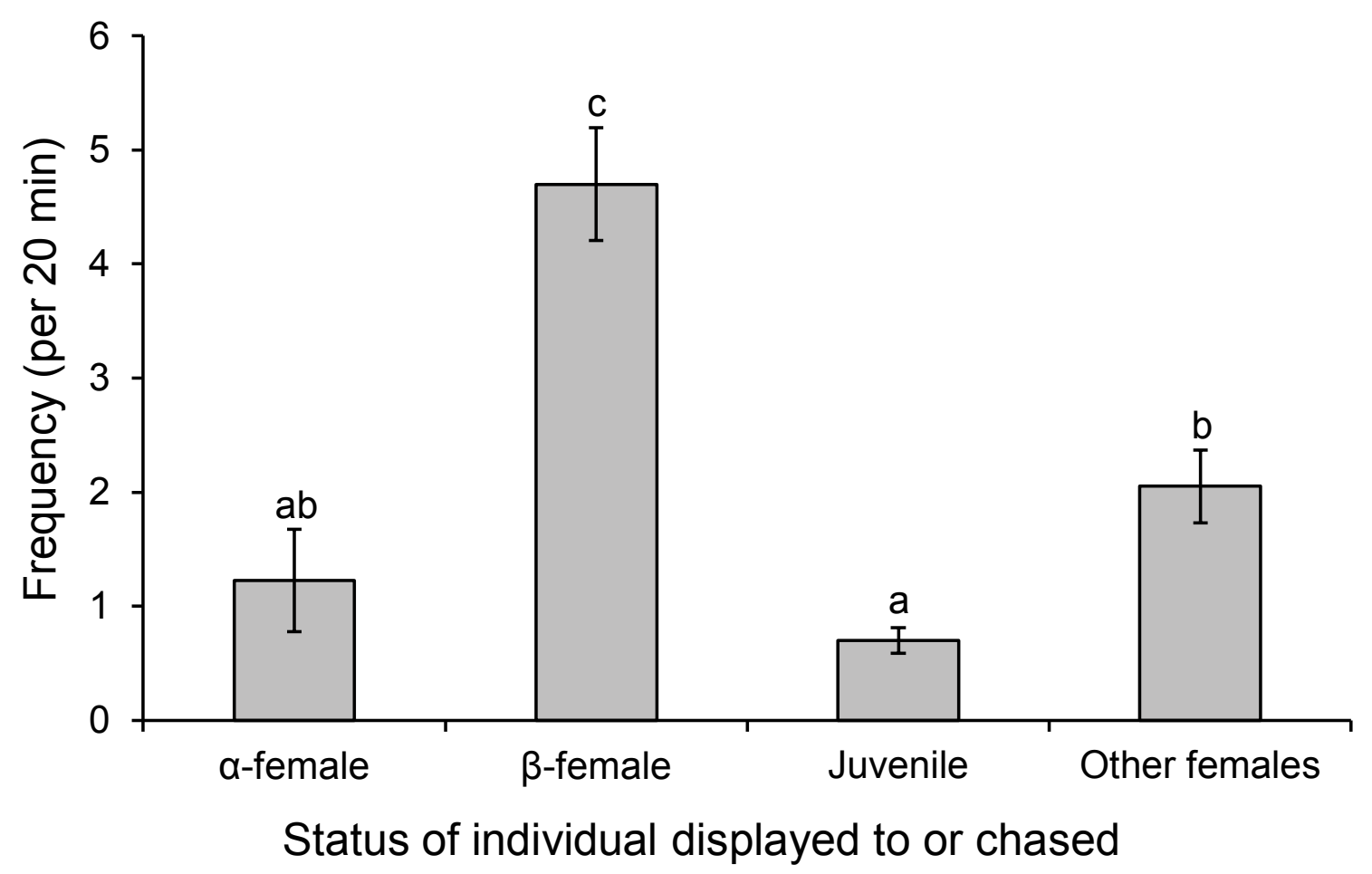

825

826 Figure 8. Males are more aggressive to subordinate females. Frequency of interactions by

827 males Pomacentrus amboinensis with females or juveniles. Errors are standard errors. Letters

828 represent Tukey's HSD groupings of means. $\mathrm{N}=10$. 
830 Figure 9

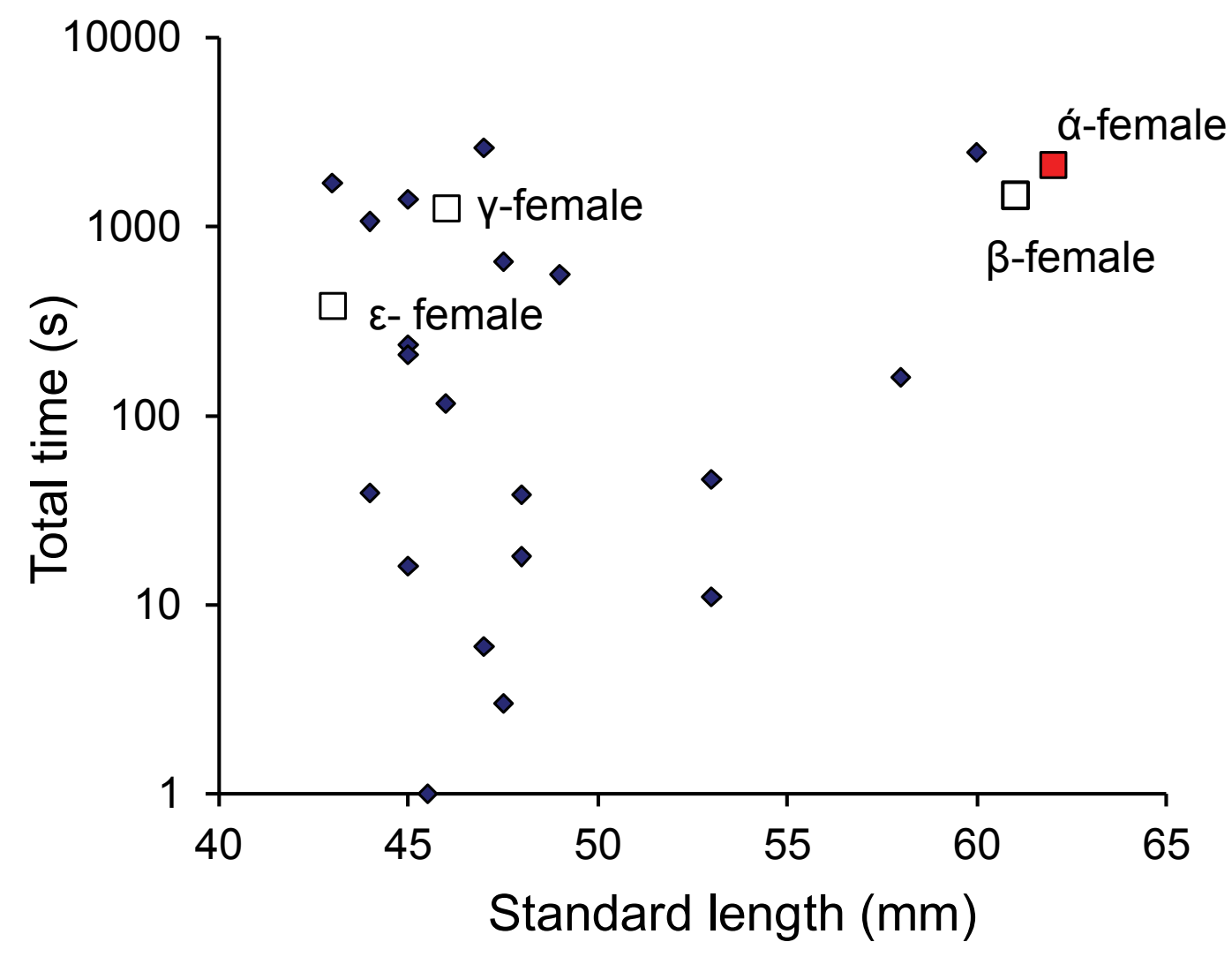

831

832

833

Figure 9. Males are promiscuous. Time spent inside the male Pomacentrus amboinensis nest by

834 females of various sizes. The dominant female $(\alpha)$ and other females primarily associated with the

835 social group are indicated (squares). Note that time is on a $\log 10$ scale. Data are from PIT tagged

836 females entering a radio monitored nest site over a period of 9 days when eggs were present in the 837 nest.

838

839

840 
